\title{
PERANCANGAN SISTEM INFORMASI GEOGRAFIS PELAYANAN PETA TEMATIK NILAI TANAH PADA KANTOR BADAN PERTANAHAN NASIONAL KOTA SERANG
}

\author{
Sutanto $^{1}$, Widyawati ${ }^{2}$, Dodi Irawan $^{3}$ \\ Universitas Banten Jaya \\ J1. Syeh Nawawi Al-Bantani, Boru, Curug, Serang - Banten, Indonesia \\ Email: sutanto@unbaja.ac.id ${ }^{1}$, widyawati@unbaja.ac.id ${ }^{2}$, dodi irawan@gmail.com ${ }^{3}$
}

\begin{abstract}
The rapid growth of large cities is heavily influenced by the complexity of the functions that run a city or region. Growth is very rapid development in large cities make the need for land and will further increase the value of land. Needs a very high soil have a tendency value of land in major cities increased. It is influenced by growing development in the region or the city. With the increase in land value that occurs is expected to be predicted so that the increase in land value that occurs not hampers the development of the area. While Geographic Information Systems (GIS) or also known as Geographic Information System $(G I S)$, the end - the end is experienced significant development in line with advances in information technology. GIS is a computer-based information system that combines elements of the map (geographical) and information about the map (data attributes) that are designed to obtain, process, manipulate, analyze, demonstrate and display spatial data to complete the planning, process and investigate the problem. So they make a thematic map of land value that describes the amount of land value or the market price and the ground potential of a certain area, which serves as a spatial information (spatial) is Thematic Map Value of Land, as the information value of land in the city of Serang, making requires data of land prices based on market value.
\end{abstract}

Keyword : Geographic Information System, Land Values, Web GIS.

\section{PENDAHULUAN}

Perkembangan teknologi informasi diera globalisasi saat ini berlangsung sangat cepat. Teknologi informasi sudah menjadi hal yang sangat tidak asing lagi dan sebuah keharusan dalam segala aspek kehidupan. Tak hanya itu, saat ini teknologi informasi bahkan telah menjadi tulang punggung kehidupan manusia dalam penyediaan dan pemberian informasi. Keberadaan sebuah informasi yang realtime, cepat, dan akurat menjadi hal yang sangat penting bagi kelangsungan hidup manusia saat ini. Data dan informasi yang diperlukan tentu harus mudah diakses dengan efektif dan efisien oleh berbagai pihak yang berkepentingan.

Sistem Informasi Geografis (SIG) atau juga dikenal sebagai Geographic Information System (GIS) akhir-akhir ini mengalami perkembangan yang berarti 
seiring kemajuan teknologi informasi yang sangat cepat. SIG merupakan sistem infomasi berbasis komputer yang menggabungkan antara unsur peta (geografis) dan informasi tentang peta tersebut (data atribut) yang dirancang untuk mendapatkan, mengolah, memanipulasi, analisa, memperagakan dan menampilkan data keruangaan spasial (keruangan) untuk menyelesaikan perencanaan, mengolah dan meneliti permasalahan berdasarkan kebutuhannya.

Penyajian informasi spasial (keruangan) dalam bentuk peta tidak lagi eksklusif, tidak hanya untuk orang-orang yang berkecimpung dalam ilmu-ilmu keruangan (geografi, geologi, landsekap, dan lain-lain). Karena saat ini banyak pihak yang membutuhkan suatu data bukan hanya dalam bentuk tabel dan angka, tetapi juga letak atau lokasi objek tersebut. Kebutuhan akan informasi keruangan yang cepat, tepat, akurat, mudah dan murah sampai terbentuknya suatu sistem informasi keruangan berbasis komputer yang dinamakan Sistem Informasi Geografis (SIG). Sistem informasi geografis dibagi menjadi dua kelompok yaitu sistem manual (analog), dan sistem otomatis (yang berbasis digital komputer), perbedaan yang paling mendasar pada keduanya adalah terletak pada cara pengelolaannnya. Sistem informasi manual biasanya menggabungkan beberapa data seperti peta, lembar transparansi untuk tumpang susun (overlay), foto udara, laporan statistik dan laporan survei lapangan, kesemua data tersebut di kompilasi dan di analisis dengan alat tanpa menggunakan komputer. Sedangkan sistem informasi geografis otomatis telah menggunakan komputer sebagai sistem pengolah data melalui proses digitasi. Sumber data digital dapat berupa citra satelit atau foto udara digital serta foto udara yang terdigitasi.

Salah satu pemanfaatan sistem informasi geografis pada Kantor Pertanahan Kota Serang adalah pelayanan peta tematik informasi nilai tanah. Peta tematik nilai tanah adalah gambaran dari nilai dan potensi tanah di suatu wilayah yang batasannya bersifat imajiner ataupun nyata sesuai dengan penggunaan tanah dan mempunyai perbedaan nilai antara satu dengan yang lainnya berdasarkan analisis nilai pasar pada saat itu, serta menggunakan peta dengan skala 1:25.000 atau lebih besar yang disesuaikan dengan luasan wilayah penelitian. Pembuatan peta tematik informasi nilai tanah ini berdasarkan beberapa kebijakan yang telah dirancang pemerintah pada sektor pertanahan, yang mengatur tentang rencana pengelolaan terpadu yang dijalankan oleh Badan Pertanahan Nasional Republik Indonesia. Berdasarkan PP13 
tahun 2010 tentang jenis dan tarif atas jenis Penerimaan Negara Bukan Pajak (PNBP) yang berlaku pada Badan Pertanahan Nasional serta peraturan yang dimandatkan dalam Perpres Nomor 10 tahun 2006, yaitu menyelenggarakan kebijakan dan pengelolaan pertanahan secara nasional, regional, dan sektoral termasuk di dalamnya hal pelaksanaan survei dan pemetaan peta tematik dan potensi tanah.

Hal ini didasari seiring perkembangan pembangunan kota yang semakin pesat dan tingginya laju pertumbuhan penduduk yang menjadi faktor pendorong meningkatnya kebutuhan tanah di perkotaan, sementara tanah yang tersedia di perkotaan terbatas. Hal ini menimbulkan permasalahan pada tanah di perkotaan, seperti peningkatan harga tanah yang tak terkendali. Belum lagi banyaknya para pelaku spekulan tanah yang membeli dengan harga yang murah dan menjual kembali dengan harga yang tinggi, akibat kurangnya informasi nilai tanah yang didapat masyarakat di daerah yang bersangkutan, serta lamanya waktu dalam pelayanan informasi nilai tanah yang biasanya dijadikan sebagai acuan oleh masyarakat ketika akan melakukan transaksi jual beli. Ketersediaan peta tematik informasi nilai tanah ini sangat diperlukan dalam pengendalian harga tanah yang senantiasa berubah akibat berbagai kepentingan dalam penggunaan tanah maka informasi tentang nilai tanah yang obyektif sangat diperlukan.

Menghadapi permasalahan pertanahan tersebut, Badan Pertanahan Nasional Republik Indonesia terus mengembangkan sistem penilaian yang merupakan modal awal terwujudnya peta tematik nilai tanah yang bersifat tunggal untuk seluruh data pertanahan, yang nantinya dapat diakses oleh berbagai lembaga tertentu seperti, Dinas Tata Ruang, perpajakan, agunan kredit bank, notaris, ganti rugi dalam pembebasan tanah, sehingga akan terjadi Data Sharing (saling berbagi data) dalam pengolahan dan penggunaan data terkait dengan pertanahan.

Peta Tematik nilai tanah ini sangat diperlukan dalam perkembangan pembangunan yang semakin pesat. Untuk memperoleh informasi nilai tanah diperlukan sebuah peta tematik nilai tanah yang terintegrasi yang mampu mengelola dan menampilkan baik data spasial maupun data atribut secara efektif dan efisien, serta untuk menghindari permainan harga jual tanah oleh para spekulan tanah, dimana akan berpengaruh pada para investor yang akan menanamkan modal di Kota Serang serta kebutuhan informasi yang cepat tepat dan akurat menjadikan pelayanan peta tematik informasi nilai tanah ini sangat berguna demi mencerminkan nilai harga 
pasar nyata dan keadilan memperoleh penilaian kepemilikan tanah secara obyektif dan transparan.

\section{A. Tinjauan Pustaka}

Penelitian ini membahas tentang Peta Tematik Nilai Tanah berbasis Geographic Information System dengan beberapa Sub kegiatan sebagai berikut: Pengolahan Data Permohonan, Proses Buat STTD, Proses Buat Surat Perintah Setor (SPS), Proses Buat Kwitansi, Proses Buat Surat Perintah Tugas (SPT), Proses Olah Data Survei, Buat Peta Informasi Tanah, Proses Buat Laporan Permohonan, Proses Buat laporan Peta Informasi Nilai Tanah. Pada penelitian ini menggunakan metode peniitian deskriptif, sedangkan dalam rangka pengembangan aplikasi menggunakan metode Rapid Aplication Development.

Perancangan software aplikasi menggunakan bahasa pemrograman Visual Studio, sedangkan database yang digunakan adalah MySql berbasis Client-Server.

\section{B. Tujuan Penelititian}

1) Mempermudah masyarakat dalam mengakses sebuah sistem pelayanan peta tematik nilai tanah melalui web browser.

2) Bagi Instansi/objek penelitian, diharapkan dapat memberikan masukan dari hasil penelitian yang berguna bagi perbaikan dan pengembangan instansi agar lebih baik di masa akan datang.

\section{Manfaat Penelitian}

Manfaat yang didapatkan dari hasil penelitian ini adalah ke depan dapat membantu masyarakat untuk memperoleh informasi tentang nilai aset tanah. Hal ini dipicu setiap daerah memiliki standar harga tanah masing-masing dan banyak sekali aspek yang menyebabkan nilai tanah yang selalu mengalamai kenaikan.

\section{METODOLOGI PENELITIAN}

Metodologi pengembangan perangkat lunak yang mendasari pembangunan sistem ini adalah System Development Life Cycle (SLDC), SDLC terdiri dari beberapa tahapan-tahapan berdasarkan analisa kebutuhan yang ada. System 
development life cycle dapat juga dianggap sebagai kerangka kerja tertua metodologi untuk membangun sistem informasi. Ide utama dari SLDC adalah untuk mengejar pengembangan sistem informasi dengan cara yang terstruktur dan metodis, yang mengharuskan tahap life cycle dari mulai ide awal sampai pada pengiriman tahap final sistem, untuk dilaksanakan secara beraturan. Salah satu tipe SLDC yang paling awal dan paling banyak digunakan adala metode Waterfall.

Waterfall methode sering dianggap sebagai pendekatan klasik dengan siklus hidup pengembangan sistem. Pengembangan dengan Waterfall memiliki tujuan yang berbeda untuk setiap fase. Setelah melakukan implementasi, maka proses tersebut akan dikembalikan kembali ke dalam tahap desain untuk pengembangan kembali. Terdapat banyak metode untuk mendeskripsikan SLDC ini, akan tetapi pada dasarnya setiap metode menggambarkan tahapan-tahapan sebagai berikut:

1) Perancangan Sistem,

Tujuan perancangan sistem adalah untuk menentukan dan mendefinisikan sistem informasi apa yang akan dikembangkan sehingga dapat memberikan keuntungan dan nilai bagi kegiatan secara keseluruhan.

2) Analisis Sistem

Tahap ini merupakan tahap preliminary dari pembuatan suatu software. Pada tahap ini dikembangkan suatu rancang bangun dari suatu software, analisis sistem juga dapat didefinisikan sebagai pengguna dari suatu sistem informasi yang utuh ke dalam bagian-bagian komponen dengan maksud untuk mengidentifikasi dan mengevalusi permasalahan-permasalahan, hambatan-hambatan, yang terjadi dan kebutuhan-kebutuhan yang diharapkan, sehingga dapat diusulkan perbaikanperbaikan. Tahap ini merupakan tahap-tahap yang kritis dan penting karena kesalahan pada tahap ini akan menyebabkan kesalahan pada tahap berikutnya. Langkah-langkah dasar yang harus dilaksanakan oleh analis sistem yaitu: a) mengidentifikasi masalah; b) memahami sistem dan membatasinya; c) alternatifalternatif apa saja yang ada untuk mencapai sasaran dan untuk memodifikasi atau mengubah sistem.

3) Desain Sistem

Tahapan perancangan memiliki tujuan untuk mendesain sistem baru yang dapat menyelesaikan masalah-masalah yang dihadapi perusahaan yang diperoleh dari pemilihan alternatif sistem yang terbaik setelah melakukan identifikasi serta 
analisis sistem, tahap selanjutnya adalah menerjemahkan konsep-konsep tersebut kedalam suatu sistem yang berwujud.

4) Implementasi Sistem

Tahap implementasi memiliki beberapa tujuan, yaitu untuk melakukan kegitan kegiatan spesifikasi rancangan logical ke dalam kegiatan yang sebenarnya dari sistem informasi yang akan dibangunnya lalu mengimplentasikan sistem yang baru tersebut ke dalam salah satu bahasa pemograman yang paling sesuai. Pada tahap ini juga harus dijamin bahwa sistem yang baru dapat berjalan secara optimal. Kegiatan yang dilakukan dalam tahap implementasi ini adalah pembuatan pemograman dan test data, pelatihan dan pergantian sistem.

5) Perawatan dan Pengembangan Sistem

Diperlukan adanya kegiatan tambahan setelah sistem yang baru dijalankan, seperti merawat dan menjaga agar sistem tetap berjalan sesuai dengan apa yang dikehendaki. Perlu juga diperhatikan akibat adanya kebijaksanaan yang baru yaitu perubahan-perubahan prosedur, agar sistem tetap menjalankan fungsinya sehingga pengembangan sistem diperlukan.

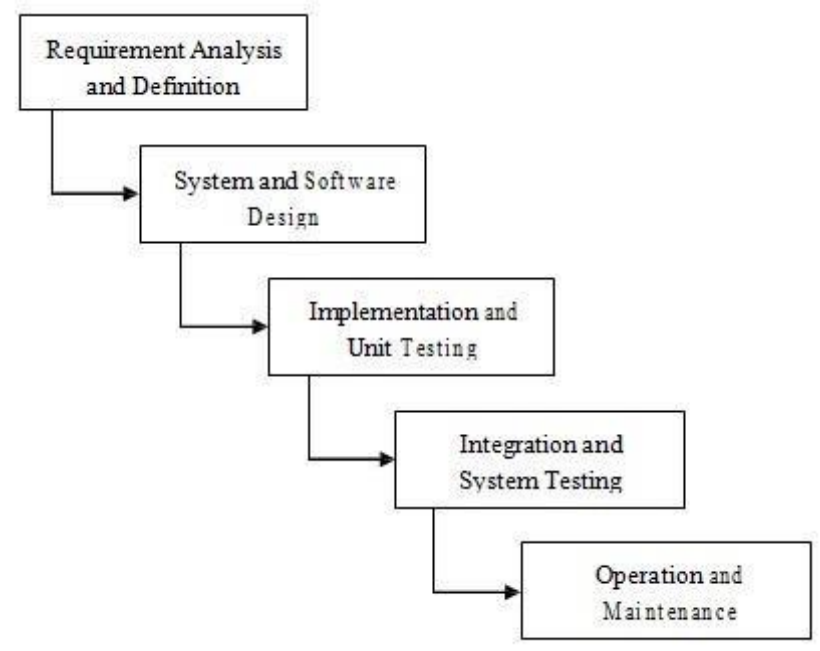

Gambar 1. Diagram Waterfall

SLDC adalah tahapan-tahapan pekerjaan yang dilakukan oleh analis sistem dan programmer dalam membangun sistem informasi, langkah yang digunakan meliputi: 
a) Melakukan survei dan menilai kelayakan proyek pengembangan sistem informasi.

b) Mempelajari dan menganalisis sistem informasi yang sedang berjalan.

c) Menentukan permintaan pemakai sistem informasi.

d) Memilih solusi atau pemecah masalah yang paling baik.

e) Menentukan perangkat keras (hardware) dan perangkat lunak (software).

f) Merancang sistem informasi baru.

g) Membangun sistem informasi baru.

h) Mengkomunikasikan dan mengimplementasikan sistem informasi baru.

i) Memelihara dan melakukan perbaikan atau peningkatan sistem baru bila diperlukan.

Adapun kegunaan utama dari SLDC adalah mengakomodasi beberapa kebutuhan. Kebutuhan-kebutuhan itu biasanyan berasal dari kebutuhan pengguna akhir dan juga pengadaan perbaikan sejumlah masalah yang terkait dengan pengembangan perangkat lunak. Semua itu dirangkum pada proses SLDC yang berupa penambahan fitur baru atau kemampuan pengguna, baik itu secara modular atau instalasi parsial atau update dan upgrade perangkat lunak maupun dengan proses instalasi baru atau penggantian perangkat lunak menyeluruh atau software replacement. Dari proses SLDC juga berapa lama umur perangkat lunak dapat diperkirakan untuk dipergunakan yang dapat diukur atau disesuaikan dengan kebijakan dukungan atau software support dari pengembang perangkat lunak terkait.

\section{HASIL DAN PEMBAHASAN}

\section{A. Metode Pendekatan dan Pengembangan Sistem Infromasi}

Dalam pembuatan sistem informasi, perlu digunakan suatu metodologi yang dapat digunakan sebagai pedoman bagaimana dan apa yang harus dikerjakan selama pembuatan sistem; antara lain, metode pendekatan sistem dan pengembangan sistem. Dalam penelitian ini metode pendekatan sistem yang digunakan ialah metode pendekatan terstruktur dan untuk mengembangkan sistem informasinya menggunakan metode pengembangan waterfall.

Pendekatan terstruktur dilengkapi alat bantu (tools) seperti Flow Map, Diagram Konteks, Data Flow Diagram (DFD), Kamus Data, Normalisasi, Tabel Relasi, Entity Relationship Diagram (ERD), dan teknik-teknik yang dibutuhkan dalam pengembangan sistem, sehingga hasil akhir dari sistem yang 
dikembangkan akan diperoleh sistem yang strukturnya didefinisikan dengan baik dan jelas.

\section{B. Pengujian Software}

Pengujian software adalah cara atau teknik untuk menguji perangkat lunak, mempunyai mekanisme untuk menentukan data uji yang dapat menguji perangkat lunak secara lengkap dan mempunyai kemungkinan tinggi untuk menemukan kesalahan.

Pengujian black box berusaha menemukan kesalahan dalam kategori:

- Fungsi-fungsi yang tidak benar atau hilang,

- Kesalahan interface,

- Kesalahan dalam struktur data atau akses basisdata eksternal,

- Validitasi fungsional,

- Inisialisasi dan kesalahan terminasi.

- Batasan dari suatu data

\section{Perancangan Sistem}

Sebelum dilakukan perancangan atau design terhadap peta tematik nilai tanah berbasis geographical infromation system, maka perlu dimodelkan terlebih dahulu alur dari bisnis proses yang terjadi pada Bagian Survei, Pengukuran dan pemetaan pada Kantor Pertanahan Kota Serang. Setelah dimodelkan dengan menggunakan Diagram Arus Data, maka selanjutnya data dimodelkan dengan menggunakan alat pemodelan Entity Relationship Diagram. 


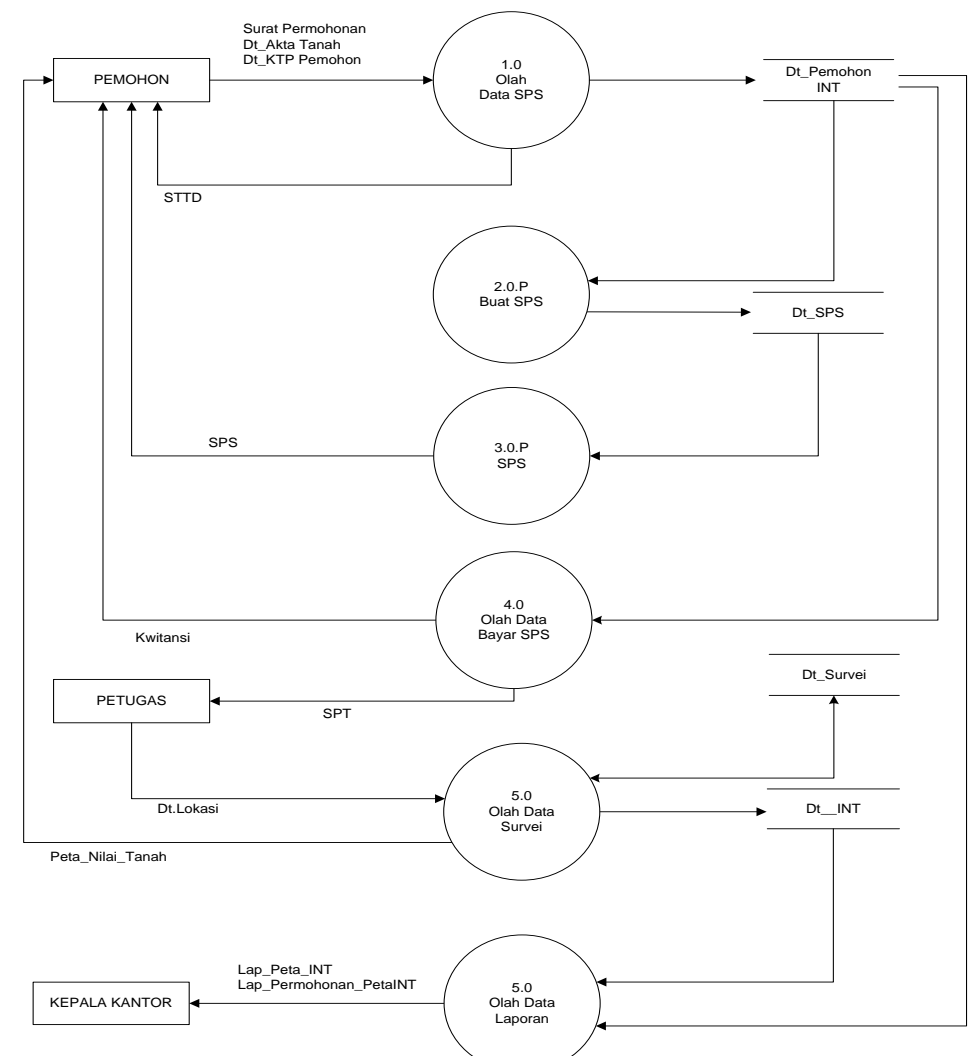

Gambar 2. Diagram Overview Sistem pelayanan Peta Tematik Nilai Tanah

\section{Perancangan Antarmuka}

Perancangan antar muka adalah merupakan tahapan desain sistem yang mempertimbangkan kemudahan user dalam menggunakan aplikasi sistem, sehingga aspek user friendly, sehingga pelibatan user dalam proses desain harus dilakukan, dan berikut adalah hasil desain interface untuk Sistem Informasi Geografis Pelayanan Peta Tematik Nilai Tanah di Kantor Pertanahan Kota Serang.

a. Struktur menu

Stuktur menu digunakan untuk memetakan aktifitas-aktifitas yang ada dalam sistem informasi sehingga memudahkan user dalam berinteraksi. Berikut adalah tampilan struktur menu pada penelitian ini: 


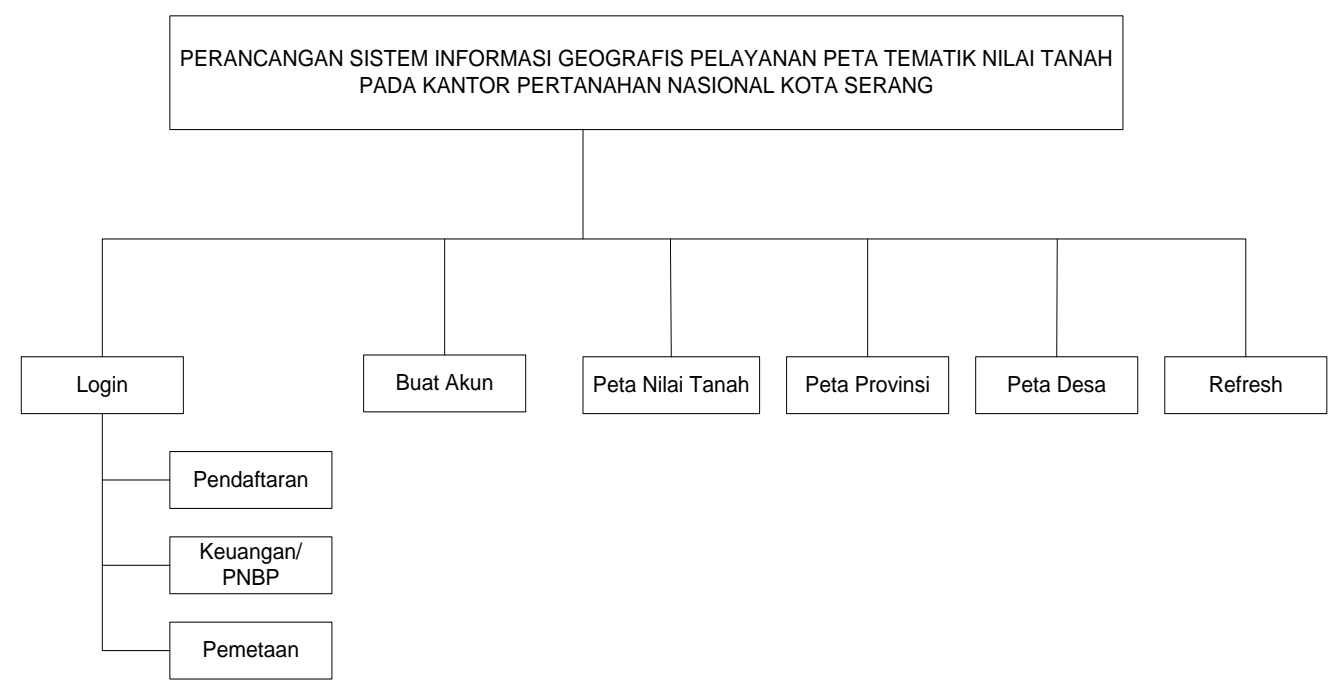

Gambar 3. Prototype Aplikasi

b. Struktur Tampilan Input / Form Input

Untuk Interface atau media pengelolaan data terdiri dari :

1. Tampilan Beranda

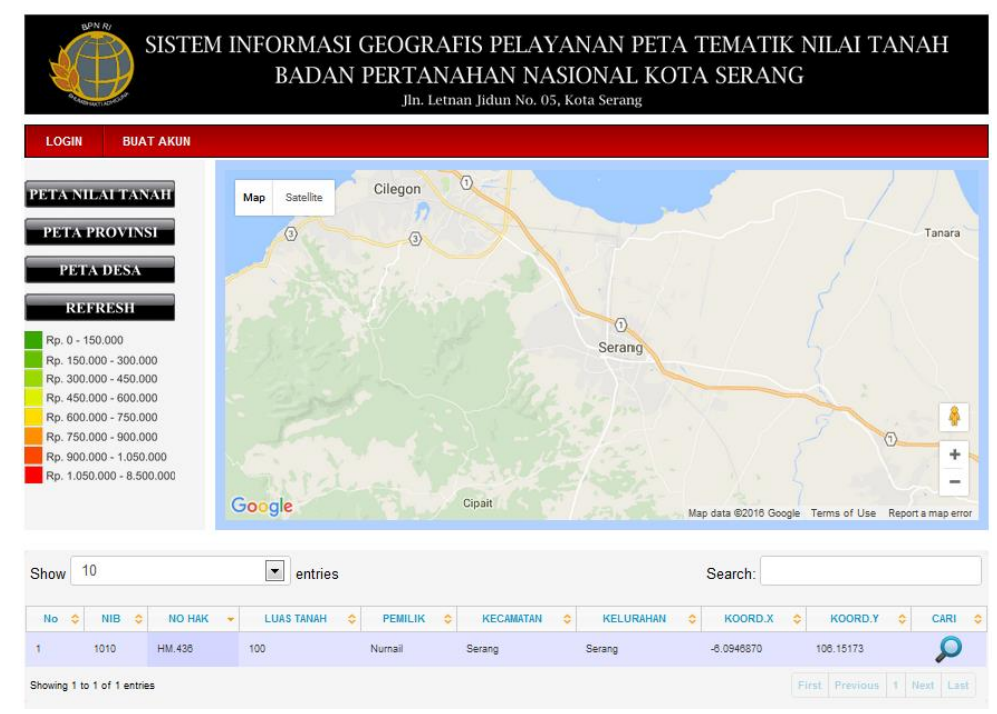

Gambar 4. Tampilan Beranda 
2. Tampilan Pendaftaran Akun

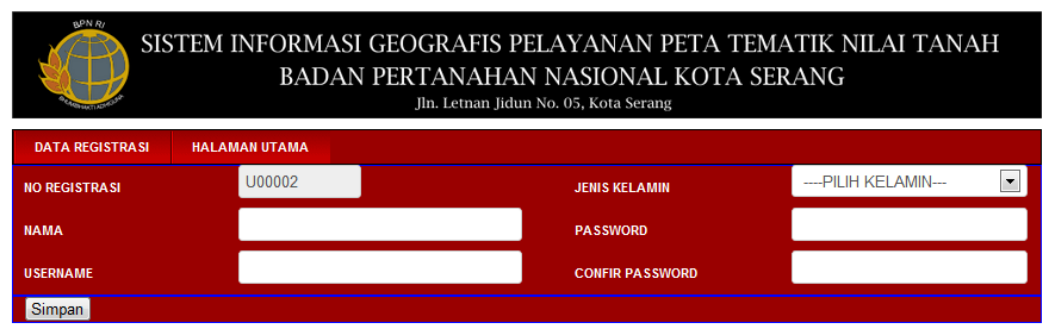

Gambar 5. Tampilan Pendaftaran Akun

3. Tampilan Upload Document

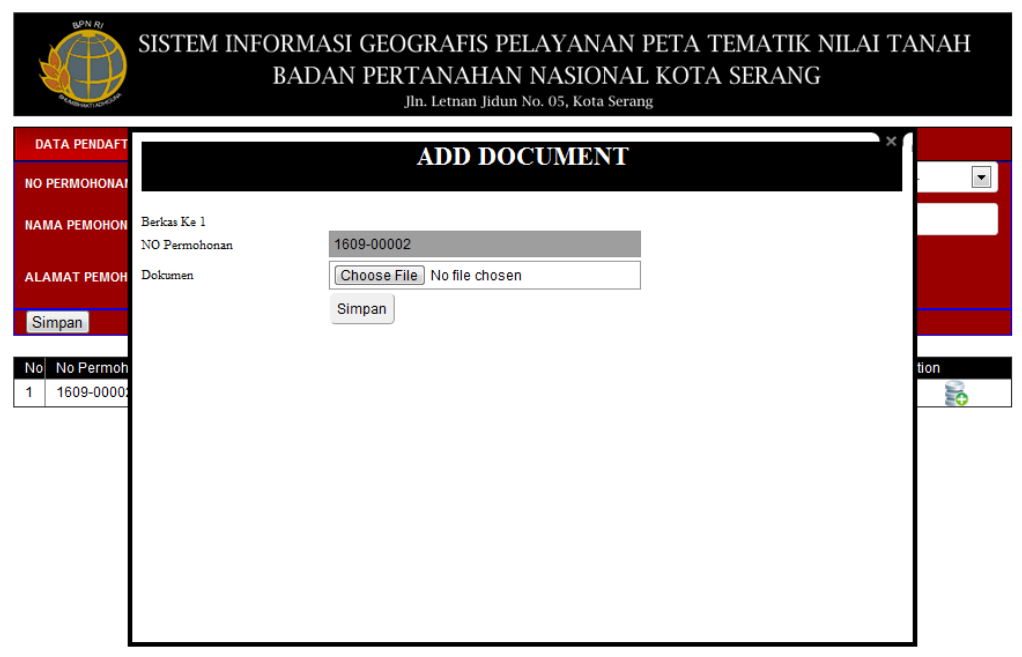

Gambar 6. Tampilan Upload Document

4. Tampilan Isi Buku Tanah

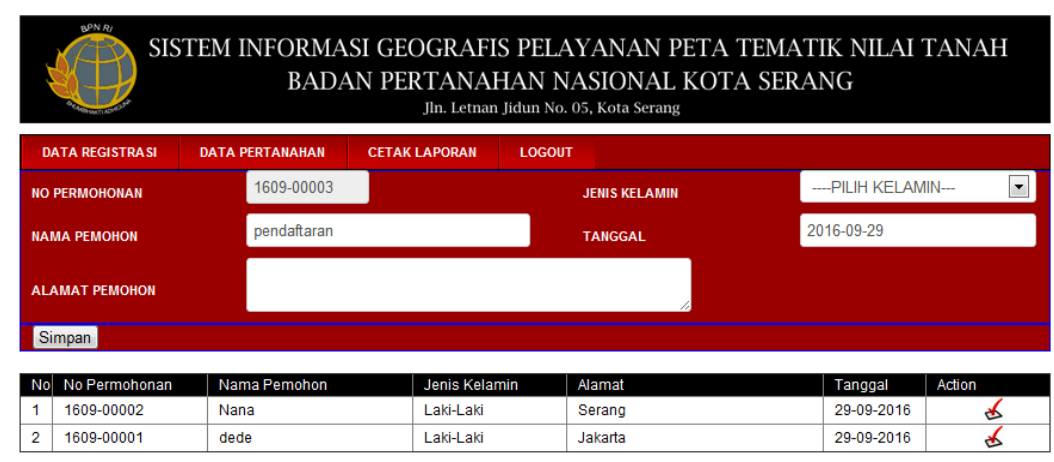

Gambar 7. Tampilan Isi Buku Tanah 
5. Tampilan Validasi Keuangan

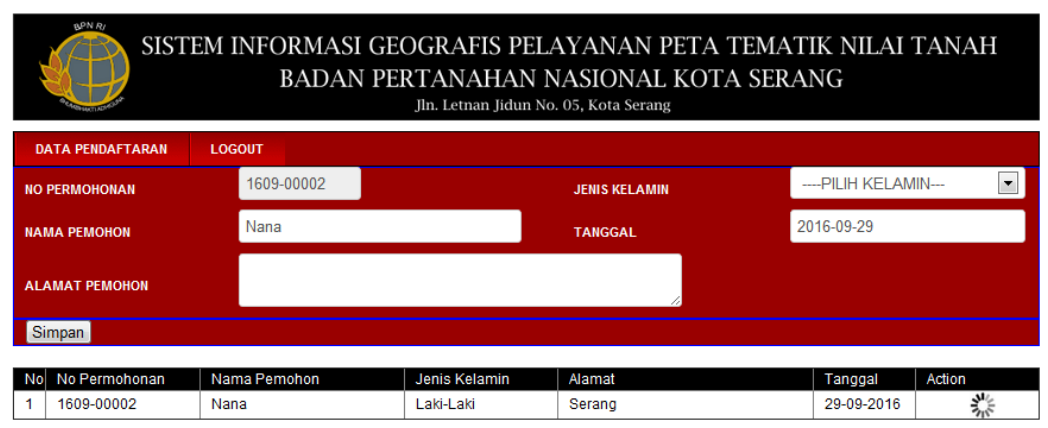

Gambar 8. Tampilan Validasi Keuangan

6. Tampilan Nilai Tanah

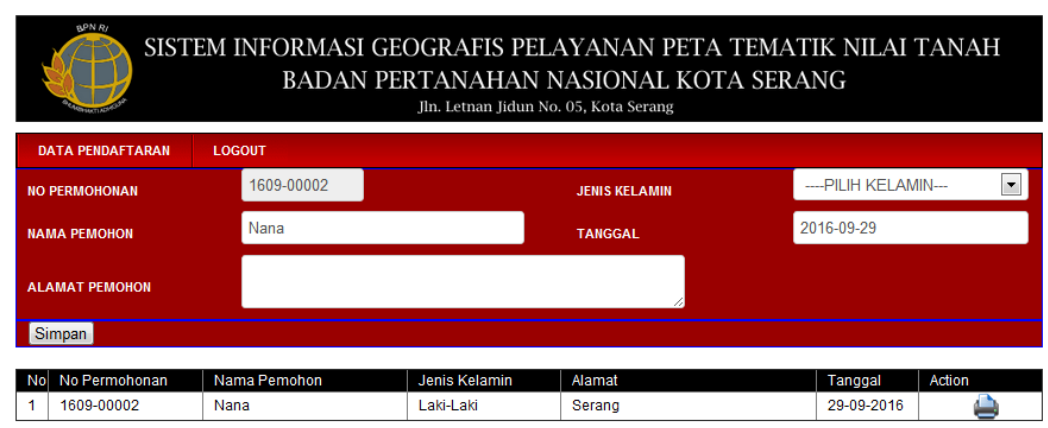

Gambar 9. Tampilan Bilai Tanah

7. Tampilan Data Buku Tanah

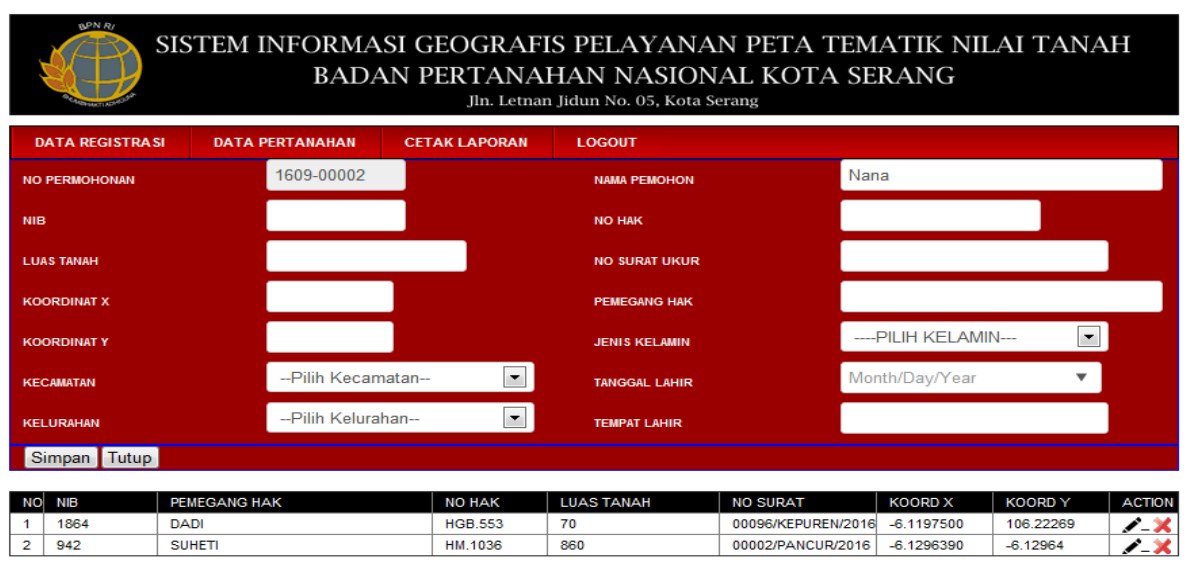

Gambar 10. Tampilan Data Buku Tanah 


\section{c. Uji Coba dan Hasil}

Uji Coba terhadap program yang penulis lakukan telah dilakukan dengan baik berdasarkan prosedur yang telah ditentukan. Pengujian dengan menggunakan black box ini bertujuan untuk menentukan langkah-langkah dalam pengujian dan memeriksa apakah ada bagian dari spesifikasi sebelumnya yang belum atau tidak diimplementasikan. Berikut ini adalah tahapan dari skenario pengujian.

Tabel 1. Pengujian Black Box Pada Sistem

\begin{tabular}{|c|c|c|c|c|c|}
\hline No & $\begin{array}{l}\text { Skenario } \\
\text { Pengujian }\end{array}$ & $\begin{array}{c}\text { Antar Muka Yang } \\
\text { Diuji }\end{array}$ & $\begin{array}{l}\text { Hasil Yang } \\
\text { Diharapkan }\end{array}$ & Hasil Pengujian & Hasil \\
\hline 1. & $\begin{array}{l}\text { Koneksi } \\
\text { Server } \\
\text { Localhost/ } \\
\text { SIG }\end{array}$ & 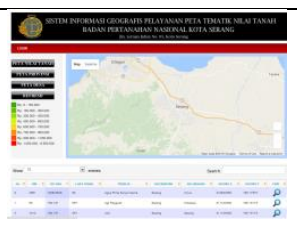 & $\begin{array}{l}\text { Tampil Layar } \\
\text { Home }\end{array}$ & - & Sesuai \\
\hline 2. & Login & & $\begin{array}{l}\text { Ketika login } \\
\text { password dan } \\
\text { username salah }\end{array}$ & 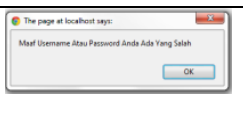 & Sesuai \\
\hline 3. & Login & & $\begin{array}{l}\text { Ketika login } \\
\text { password dan } \\
\text { username benar, } \\
\text { maka akan } \\
\text { masuk ke menu }\end{array}$ & & Sesuai \\
\hline 4. & $\begin{array}{l}\text { Proses data } \\
\text { registrasi }\end{array}$ & $=$ & $\begin{array}{l}\text { Ketika mengisi } \\
\text { data registrasi } \\
\text { maka akan } \\
\text { tampil }\end{array}$ & & Sesuai \\
\hline 5. & $\begin{array}{l}\text { Klik tombol } \\
\text { hapus }\end{array}$ & & $\begin{array}{l}\text { Akan ada } \\
\text { validasi hapus } \\
\text { data }\end{array}$ & & Sesuai \\
\hline 6. & $\begin{array}{l}\text { Klik tombol } \\
\text { Edit }\end{array}$ & & $\begin{array}{l}\text { Data akan } \\
\text { tampil dalam } \\
\text { form registrasi }\end{array}$ & E= & Sesuai \\
\hline 7. & $\begin{array}{l}\text { Pada proses } \\
\text { isi buku } \\
\text { tanah }\end{array}$ & 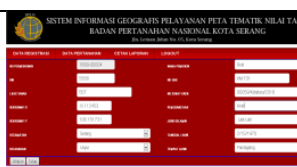 & $\begin{array}{l}\text { Ketika mengisi } \\
\text { data registrasi } \\
\text { maka akan } \\
\text { tampil }\end{array}$ & 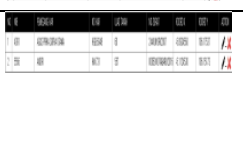 & Sesuai \\
\hline 8. & $\begin{array}{l}\text { Cetak } \\
\text { Laporan }\end{array}$ & 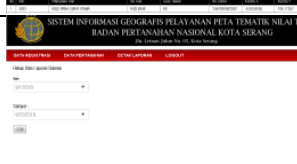 & $\begin{array}{l}\text { Cetak laporan } \\
\text { sesuaikan } \\
\text { dengan tgl } \\
\text { permohonan }\end{array}$ & 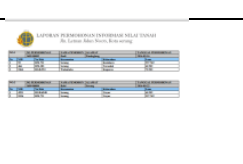 & Sesuai \\
\hline
\end{tabular}




\begin{tabular}{|c|c|c|c|c|c|}
\hline 9. & $\begin{array}{l}\text { Klik data } \\
\text { Pembayaran }\end{array}$ & 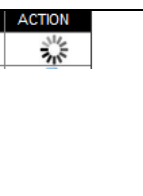 & $\begin{array}{l}\text { Ketika validasi } \\
\text { di klik maka } \\
\text { icon akan } \\
\text { berubah jadi } \\
\text { icon print }\end{array}$ & ACTON & Sesuai \\
\hline 10. & $\begin{array}{l}\text { Perintah } \\
\text { cetak }\end{array}$ & COMON & $\begin{array}{l}\text { Ketika print di } \\
\text { tekan }\end{array}$ & $\begin{array}{l}== \\
=-1 \\
=-1=\end{array}$ & \\
\hline 11. & $\begin{array}{l}\text { Klik tombol } \\
\text { untuk } \\
\text { menetukan } \\
\text { Informasi } \\
\text { nilai tanah }\end{array}$ & $\widetilde{C}$ & $\begin{array}{l}\text { Ketika print di } \\
\text { tekan }\end{array}$ & & Sesuai \\
\hline 12. & $\begin{array}{l}\text { Klik tombol } \\
\text { Edit }\end{array}$ & $\bullet$ & $\begin{array}{l}\text { Data akan } \\
\text { tampil dalam } \\
\text { form registrasi }\end{array}$ & 高 & Sesuai \\
\hline 13. & $\begin{array}{l}\text { Klik tombol } \\
\text { lihat harga } \\
\text { tanah }\end{array}$ & $\overline{0}$ & $\begin{array}{l}\text { Akan } \\
\text { menunjukan ke } \\
\text { lokasi peta nilai } \\
\text { tanah dari posisi } \\
\text { koordinat, lalu } \\
\text { isi form harga } \\
\text { tanah }\end{array}$ & & Sesuai \\
\hline 14. & $\begin{array}{l}\text { Setelah } \\
\text { terisi akan } \\
\text { berubah } \\
\text { menjadi } \\
\text { ikon print }\end{array}$ & : & $\begin{array}{l}\text { Penentuan harga } \\
\text { tanah selesai }\end{array}$ & 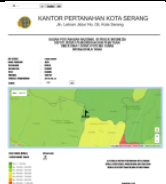 & Sesuai \\
\hline
\end{tabular}

\section{KESIMPULAN DAN SARAN}

\section{A. Kesimpulan}

Penelitian yang dilakukan dengan judul Perancangan Sistem Informasi Geografis Pelayanan Peta Temtik Nilai Tanah Pada Kantor Badan Pertanahan Kota Serang menghasilkan sistem aplikasi berbasis web yang telah diuji coba dan mampu memberikan serta mengatasi masalah di dalam pelayanan terutama dalam bidang pelayanan informasi nilai tanah. Dengan melihat perbandingan dari sistem sebelumnya yaitu:

1. Dalam hal pelayanan peta tematik nilai tanah masyarakat dapat dengan mudah memperoleh informasi nilai tanah dengan hanya membuka sebuah web browser.

2. Pemohon dapat dengan cepat mengetahui informasi nilai tanah setelah melakukan pendaftaran tanpa harus menunggu hasil cetaknya keluar. 


\section{B. Saran}

Agar sistem yang dirancang pada penelitian ini dapat berjalan dengan optimal maka beberapa saran yang sebaiknya dilakukan adalah:

1. Para pengguna sistem benar-benar menguasai sistem aplikasi, karena input yang dilakukan akan mempengaruhi proses.

2. Pemeliharaan sistem dilakukan minimal satu bulan sekali agar sistem dapat berjalan dengan optimal.

\section{DAFTAR PUSTAKA}

Adya Barata, Atep, 2003, Dasar Dasar Pelayanan Prima, PT. Elex Media Komputindo, Jakarta

Ahmad Shukri Mohd. Nain dan Ahmad Md. Rasli, 2010, Pengurusan Teknologi, Universiti Teknologi Malaysia, Kuala Lumpur, Malaysia

Al Fatta, Hanif, 2007, Analisa dan Perancangan Sistem Infromasi, Andi Offset Yogyakarta, Yogyakarta.

Binanto, Iwan, 2010, Multimedia Digital Dasar Teori dan Pengembangan, Andi Offset, Yogyakarta.

Budiyanto, Eko, 2002, Sistem Informasi Geografis menggunakan Arc View Gis, Andi Offset, Yogyakarta

Darji, Darmodiharjo, and Shidarta, 2006, Pokok-Pokok Filsafat Hukum Apa dan Bagaimana Filsafat Hukum Indonesia, Gramedia Pustaka Utama. Jakarta

Irwansyah Edy, 2013, Sistem Informasi Geografis, Prinsip dasar dan Pengembangan Aplikasi, Digibooks, Yogyakarta, Yogyakarta.

Jogiyanto, H.M, 2009, Analisis dan Desain Sistem Informasi Terstruktur, Andi Offset, Yogyakarta.

-----------, 2005, Analisa dan Desain Sistem Informasi, Andi Offset, Yogyakarta.

Khosim, Amir., and Marlina Lubis, Kun, 2006, Geografi, Grasindo, Jakarta

Kamus besar bahasa Indonesia, 2016, http://kbbi.web.id/layan, diakses tanggal 21/07/2016 Jam 09:00

Ladjamudin, Al-Bahra Bin, 2005, Analisis \& Desain Sistem Informasi Perancangan, Graha Ilmu, Yogyakarta 